\title{
A flexible and superhydrophobic upconversion- luminescence membrane as an ultrasensitive fluorescence sensor for single droplet detection
}

\author{
Kui-Chao Liu ${ }^{1}$, Zhen-Yi Zhang ${ }^{1}$, Chong-Xin Shan ${ }^{2,3}$, Zhi-Qing Feng ${ }^{1}$, Jia-Su Li ${ }^{1}$, Chun-Lei Song1, Ya-Nan Bao ${ }^{1}$, \\ Xiao-Hui $\mathrm{Qi}^{1}$ and Bin Dong ${ }^{1}$
}

A $\mathrm{Ln}^{3+-}$-doped $\left(\mathrm{Yb}^{3+}, \mathrm{Tm}^{3+}\right.$ or $\mathrm{Yb}^{3+}, \mathrm{Er}^{3+}$ co-doped) $\mathrm{NaYF}_{4}$ nanoparticle/polystyrene hybrid fibrous membrane (HFM) was fabricated using an electrospinning technique. The HFM shows upconversion luminescence (UCL), flexibility, superhydrophobicity and processability. The UCL membrane can be used as a fluorescence sensor to detect bioinformation from a single water droplet $(\sim 10 \mu \mathrm{l})$. Based on the fluorescence resonance energy transfer, the detection limits of this sensor can reach 1 and $10 \mathrm{ppb}$ for the biomolecule, avidin, and the dye molecule, Rhodamine B, respectively, which are superior to most of the fluorescence sensors reported in previous works. After the fluorescence detection, the target droplet was easily removed without residues on the UCL membrane surface due to its superhydrophobic property, which exhibits an excellent recyclability that cannot be achieved by traditional liquid-based detection systems.

Light: Science \& Applications (2016) 5, e16136; doi:10.1038/lsa.2016.136; published online 12 August 2016

Keywords: electrospinning; fibrous membrane; fluorescence resonance energy transfer; fluorescence sensor; superhydrophobic surface; upconversion luminescence

\section{INTRODUCTION}

Biological or medical detection by using reliable fluorescence materials as a probe has attracted growing attention in recent years because it can effectively sense the available information from the target solution within a very short time ${ }^{1-5}$. In recent years, upconversionluminescence (UCL) materials have attracted increasing interest for upconversion lasers, solar cells, photocatalysis, and biological labeling and sensing ${ }^{6-12}$. Compared with traditional single-photon-excited fluorescence materials, such as semiconductor quantum dots and organic fluorophores, UCL materials exhibit numerous advantages for potential applications in a luminescent biosensor, including high sensitivity, minimum photodamage to living organisms, weak autofluorescence, etc ${ }^{13-16}$. Among the UCL nanomaterials, $\mathrm{NaYF}_{4}$ nanoparticles (NPs) co-doped with trivalent lanthanide ions $\left(\mathrm{Ln}^{3+}\right)$ are regarded as the most promising. This is because the $\mathrm{Yb}^{3+}$ ions serve as a sensitizing agent to hold multiple near-infrared photons that then transfer to the luminescence center of neighboring $\mathrm{Er}^{3+}\left(\right.$ or $\mathrm{Tm}^{3+}$ ) ions, resulting in efficient light emission in the visible region ${ }^{17-21}$. Although the $\mathrm{Ln}^{3+}$ co-doped $\mathrm{NaYF}_{4} \mathrm{NPs}$ that have high surface areas can be easily dispersed in the liquid phase to initiate the UCL biodetection due to the fluorescence resonance energy transfer (FRET) between the upconversion-luminescence nanoparticle (UCLNP) (donor) and the chromophores (acceptor), these particulate sensors, when suspended in a target solution, are usually unstable, irreproducible and exhibit poor processability ${ }^{22-29}$. Therefore, it is important to develop a novel free-standing solid UCL sensor that possesses not only ultrahigh sensitivity but also excellent recyclability and tailorability.

The assembly of individual UCLNPs into transparent polymer nanostructures to construct an inorganic/organic hybrid material on the macroscopic scale is an efficient strategy to achieve a highperformance UCL biosensor that satisfies the above required advantages. This hybrid material can integrate the properties of both the inorganic UCLNPs (two- or multi-photon absorption and antistokes shift behaviors) and the organic polymer (lightweight, flexibility and processability $)^{30-33}$. To develop the recycling characteristics, the UCLNPs should be coated with a hydrophobic polymer to avoid direct contact (or interaction) between the sensitive NPs and the chromophores in aqueous solutions. Furthermore, a micro- or nano-scale polymer coating is required to produce photon energy absorption and emission of the covered UCLNPs. The challenge for these designs is the proper choice of a fabrication method for efficient self-assembly of the UCLNPs into a desirable polymer micro- or nano-matrix and their further accumulation in the macroscopic scale for UCL detection.

Electrospinning is a facile and convenient technique to produce a polymer or related hybrid fibrous membrane (HFM) by which various types of additives ranging from tiny molecules to microscopic

${ }^{1}$ Key Laboratory of New Energy and Rare Earth Resource Utilization of State Ethnic Affairs Commission, Dalian Nationalities University, 18 Liaohe West Road, Dalian 116600 , China; ${ }^{2}$ State Key Laboratory of Luminescence and Applications, Changchun Institute of Optics, Fine Mechanics and Physics, Chinese Academy of Sciences, Changchun 130033, China and ${ }^{3}$ School of Physics and Engineering, Zhengzhou University, Zhengzhou 450001, China

Correspondence: ZY Zhang, Email: zhangzy@dlnu.edu.cn; B Dong, Email: dong@dlnu.edu.cn

Received 2 November 2015; revised 6 March 2016; accepted 10 March 2016; accepted article preview online 21 March 2016 
functional NPs can be embedded into the electrospun fiber matrix to promote their functionalization ${ }^{34-38}$. Herein, we used the electrospinning technique to embed the UCLNPs clusters into the transparent polystyrene (PS) nanofibers, interweaving a flexible, free-standing and tailorable HFM, in which the UCL clusters consist of $\mathrm{NaYF}_{4}: \mathrm{Yb}^{3+}$, $\mathrm{Tm}^{3+}\left(\right.$ or $\mathrm{Er}^{3+}$ ) NPs with diameters of $35 \pm 10 \mathrm{~nm}$. Furthermore, the rational combination of the hydrophobic chemical structure of the PS with the unique morphological structure of electrospun fibrous membrane endowed UCLNPs/PS HFM with a promising superhydrophobicity with a water contact angle of $153^{\circ}$. By using the asfabricated UCLNPs/PS HFM as a free-standing solid sensor, we achieved UCL detection from a single water drop $(10 \mu \mathrm{l})$ with an ultra-low concentration of a dye molecule (10 ppb of Rhodamine B $(\mathrm{RhB})$ ) and a biomolecule (1 ppb of avidin). Such ultra-low detection limits for fluorescence molecules have been not reported to date. in addition, this high-performance UCL sensor also exhibited excellent recyclability due to its superhydrophobic self-cleaning surface.

\section{MATERIALS AND METHODS}

Synthesis of $\mathrm{NaYF}_{4} \mathrm{NPs}$ co-doped with $\mathrm{Yb}^{3+}$ and $\mathrm{Er}^{3+}$ ions

The $\mathrm{NaYF}_{4} \mathrm{NPs}$, which include $18 \% \mathrm{Yb}^{3+}$ and $2 \% \mathrm{Er}^{3+}$, were synthesized via the solvothermal method. During this synthesis process, a transparent mixture solution, which was labeled as solution A, was prepared firstly through dissolving $1.2 \mathrm{mmol}$ of $\mathrm{NaCl}$, $0.48 \mathrm{mmol}$ of $\mathrm{YCl}_{3}, 0.108 \mathrm{mmol}$ of $\mathrm{YbCl}_{3}$ and $0.012 \mathrm{mmol}$ of $\mathrm{ErCl}_{3}$ into a $9 \mathrm{ml}$ of ethylene glycol (EG) solvent. Afterwards, the other transparent solution, which was labeled as solution $\mathrm{B}$, was obtained by mixing the $3.0 \mathrm{mmol}$ of $\mathrm{NH}_{4} \mathrm{~F}$ and $0.006 \mathrm{mmol}$ of hydrophilic polyethyleneimine (PEI) in a $6 \mathrm{ml}$ of EG solvent. Subsequently, the solution A was added into the solution B to form a new mixture (precursor solution) after stirring vigorously for $10 \mathrm{~min}$. This precursor solution was then sealed into a Teflon-lined autoclave with the volume of $25 \mathrm{ml}$, and kept the temperature at $200{ }^{\circ} \mathrm{C}$ for $120 \mathrm{~min}$. Thus, the target sample with white color was achieved by centrifugation, cleaned with ethanol four times and $N, N$-dimethylformamide (DMF) twice and finally dispersed in DMF solvent.

\section{Synthesis of $\mathrm{NaYF}_{4}$ NPs co-doped with $\mathrm{Yb}^{3+}$ and $\mathrm{Tm}^{3+}$ ions} The $\mathrm{NaYF}_{4} \mathrm{NPs}$, which include $20 \% \mathrm{Yb}^{3+}$ and $0.2 \% \mathrm{Tm}^{3+}$, were synthesized using the solvothermal method. During this synthesis process, a transparent mixture solution, which was labeled as solution A, was prepared firstly through dissolving $1.2 \mathrm{mmol}$ of $\mathrm{NaCl}$, $0.48 \mathrm{mmol}$ of $\mathrm{YCl}_{3}, 0.12 \mathrm{mmol}$ of $\mathrm{YbCl}_{3}$ and $0.0012 \mathrm{mmol}$ of $\mathrm{TmCl}_{3}$ into a $9 \mathrm{ml}$ of EG solvent. Afterwards, the other transparent solution, which was labeled as solution $\mathrm{B}$, was obtained by mixing the $3.0 \mathrm{mmol}$ of $\mathrm{NH}_{4} \mathrm{~F}$ and $0.006 \mathrm{mmol}$ of PEI in a $6 \mathrm{ml}$ of EG solvent. Subsequently, the solution A was added into the solution B to form a new mixture (precursor solution) after stirring vigorously for $10 \mathrm{~min}$. This precursor solution was then sealed into a Teflon-lined autoclave with the volume of $25 \mathrm{ml}$, and kept the temperature at $200{ }^{\circ} \mathrm{C}$ for $120 \mathrm{~min}$. Thus, the target sample with white color was achieved by centrifugation, cleaned with ethanol four times and DMF twice and finally dispersed in DMF solvent.

\section{Fabrication of the UCL membranes}

Approximately $0.4 \mathrm{~g}$ of PS powder $(\mathrm{Mw}=350000)$ was dissolved into $5 \mathrm{ml}$ of the above UCL NP/DMF solution at $50^{\circ} \mathrm{C}(\sim 0.08 \mathrm{M}$ for the $\mathrm{NaYF}_{4}: \mathrm{Yb}^{3+}, \mathrm{Tm}^{3+} \mathrm{NPs}$ and for $\sim 0.1 \mathrm{M}$ of the $\mathrm{NaYF}_{4}: \mathrm{Yb}^{3+}, \mathrm{Er}^{3+}$ NPs). This composite solution was then transferred to a plastic syringe for electrospinning. The applied negative voltage was fixed at $10 \mathrm{kV}$, and the collection distance was chose at $15 \mathrm{~cm}$. Thus, the $\mathrm{NaYF}_{4}: \mathrm{Yb}^{3+}$,
$\mathrm{Tm}^{3+}$ and the $\mathrm{NaYF}_{4}: \mathrm{Yb}^{3+}, \mathrm{Er}^{3+}$ NPs-embedded PS electrospun nanofibers were fabricated to produce upconversion blue emission and green emission membranes, respectively.

\section{Characterization}

The phase structures of the as-synthesized products were investigated by $\mathrm{X}$-ray diffraction $(\mathrm{XRD})$ technique $(\mathrm{Cu} \mathrm{K} \alpha$ line at $0.1541 \mathrm{~nm}$; XRD-6000, Shimadzu, Japan). The surface morphologies of these products were observed by a field emission scanning electron microscopy (FE-SEM) (S-4800, Hitachi, Japan), and their inner micro-structures were revealed by a transmission electron microscopy (TEM) (JEM-2100, JEOL, Japan). The optical properties of these products were detected by a Lambda 750 UV-Vis-NIR spectrophotometer (Perkin-Elmer, USA). The fluorescence spectra were recorded using a F4600 fluorimeter (Shimadzu, Japan). The water contact angles of the products were measured with a droplet analysis system (DSA100, Kruss, Germany) at five different points.

\section{Fluorescence detection on a single water droplet}

A schematic diagram of the fluorescence measurement is presented in Figure $3 \mathrm{c}$ in which the optical signals generated from both the UCL membrane and the detecting droplet are investigated simultaneously. The as-fabricated membrane was put onto the upside of a glass slide, and an intersection angle of $45^{\circ}$ was maintained between this glass slide and the incident laser (980-nm diode). Then, a water droplet $(10 \mu \mathrm{l})$ containing a certain concentration of avidin or $\mathrm{RhB}$ was dropped onto the membrane surface. The continuous $980-\mathrm{nm}$ diode laser was used to pump the droplet position of the membrane surface, and the corresponding signal was collected using an iHR 550 spectrometer located along the vertical direction of the incident laser at a spectral resolution of $0.1 \mathrm{~nm}$. All of the measurements were conducted at room temperature.

\section{RESULTS AND DISCUSSION}

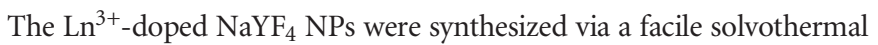
method with hydrophilic PEI as the surfactant to guide the growth of the crystals, and the upconversion (UC) emission spectra were finely tuned from the visible to near-infrared region by modulating the ratios or species of the dopants $\left(\mathrm{Yb}^{3+}, \mathrm{Tm}^{3+}\right.$ and $\left.\mathrm{Er}^{3+}\right)$ in the $\mathrm{NaYF}_{4}$ host lattice ${ }^{17}$. Meanwhile, the synthesized $\mathrm{Ln}^{3+}$-doped $\mathrm{NaYF}_{4} \mathrm{NPs}$ were well-dispersed in the solvent of DMF. This provided a favorable opportunity for electrospinning of the UCLNPs/PS HM due to the good solubility of the PS polymer in the DMF solvent. Thus, the assynthesized UCLNPs were centrifuged to remove the excess residual surfactant and solvent and then dispersed in DMF solution. To manifest strong UC emission intensity, a high concentration of $\mathrm{Ln}^{3+}$-doped $\mathrm{NaYF}_{4} \mathrm{NPs}$ was required $\left(\sim 0.08 \mathrm{M}\right.$ for the $\mathrm{NaYF}_{4}: \mathrm{Yb}^{3+}$, $\mathrm{Tm}^{3+} \mathrm{NPs}$ and $\sim 0.1 \mathrm{M}$ for the $\left.\mathrm{NaYF}_{4}: \mathrm{Yb}^{3+}, \mathrm{Er}^{3+} \mathrm{NPs}\right)$. Afterwards, the PS polymer, the host matrix, was also dissolved into the UCLNPsuspended solution to obtain the electrospun precursor solution. After electrospinning this viscous solution, the UCLNPs could be assembled within the PS nanofibers, which then interweaved to form a HFM. In our present work, the $\mathrm{NaYF}_{4}: \mathrm{Yb}^{3+}, \mathrm{Tm}^{3+}$ and $\mathrm{NaYF}_{4}: \mathrm{Yb}^{3+}, \mathrm{Er}^{3+} \mathrm{NP}-$ embedded PS electrospun nanofibers were fabricated to produce blue and green UCL membranes, respectively. The UCL originated from the embedded $\mathrm{NaYF}_{4}: \mathrm{Yb}^{3+}, \mathrm{Tm}^{3+}\left(\mathrm{Er}^{3+}\right) \mathrm{NPs}$, which allowed the aselectrospun HFM to be used as a UCL sensor with high sensitivity. Furthermore, because of the intrinsic nature of the PS nanofibrous framework, the free-standing HFM is also flexible and freely tailorable.

Figure la shows the TEM image of the as-synthesized $\mathrm{NaYF}_{4}: \mathrm{Yb}^{3+}$, $\mathrm{Tm}^{3+}$ NPs. The particles are spherical in shape with an average diameter of $35 \pm 10 \mathrm{~nm}$. The high-resolution TEM (HRTEM) image 

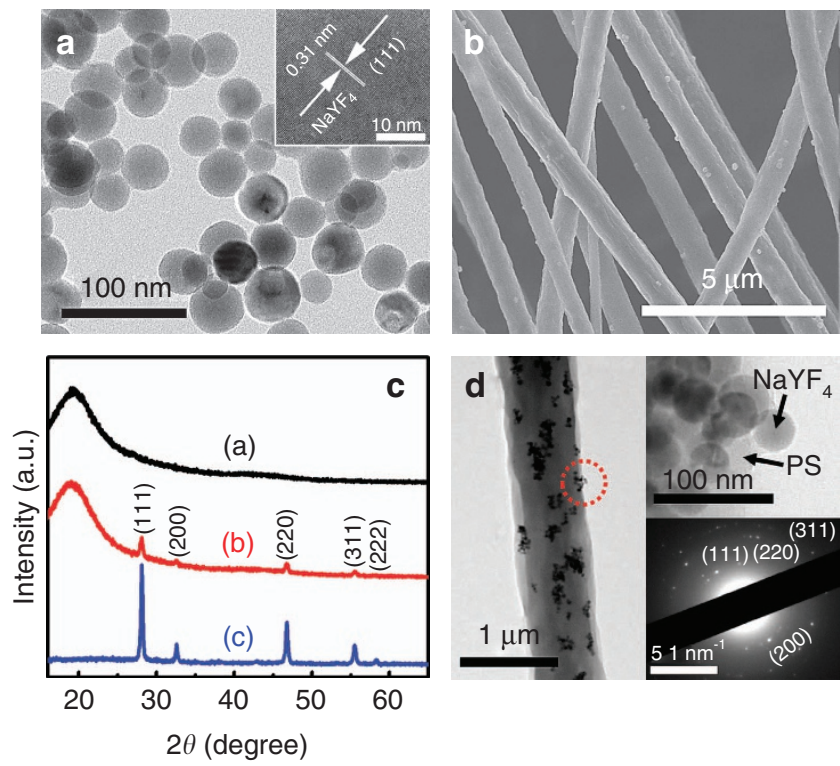

Figure 1 (a) TEM image of the as-synthesized $\mathrm{NaYF}_{4}: \mathrm{Yb}^{3+}, \mathrm{Tm}^{3+} \mathrm{NPs}$; the inset shows the HRTEM image of the NPs; (b) SEM image of the aselectrospun $\mathrm{NaYF}_{4}: \mathrm{Yb}^{3+}, \mathrm{Tm}^{3+} / \mathrm{PS}$ hybrid nanofibers; (c) XRD patterns of the as-fabricated samples: (a) PS nanofibers; (b) $\mathrm{NaYF}_{4}: \mathrm{Yb}^{3+}, \mathrm{Tm}^{3+} / \mathrm{PS}$ hybrid nanofibers; (c) $\mathrm{NaYF}_{4}: \mathrm{Yb}^{3+}, \mathrm{Tm}^{3+} \mathrm{NPs}$; (d) low and high magnification of the TEM image of an individual $\mathrm{NaYF}_{4}: \mathrm{Yb}^{3+}, \mathrm{Tm}^{3+} / \mathrm{PS}$ hybrid nanofiber and the corresponding SAED pattern.

displays a lattice fringe with a $d$-spacing of $0.31 \mathrm{~nm}$, which corresponds to the (111) planes of the cubic $\mathrm{NaYF}_{4}$ crystal. After assembling the as-synthesized UCLNPs in the PS matrix using the electrospining technique, one-dimensional hybrid nanofibers with a diameter of $600 \sim 800 \mathrm{~nm}$ and a length of several tens of micrometers were fabricated (Figure 1b). Meanwhile, some of the spherical NPs were observable on the nanofiber surfaces, which may be due to a combination effect that is based on three aspects ${ }^{34-38}$ : (1) the high viscosity of the electrospun precursor solution; (2) the high concentration of the UCLNPs in the hybrid nanofibers and (3) the fast resolidification of the PS polymer during the electrostatic drawing process. XRD patterns of the as-fabricated samples are shown in Figure $1 \mathrm{c}$ in which a broad peak appeared at $20^{\circ}$ on the curve of the pure PS nanofibers, which can be ascribed to the semicrystallinity of the polymer. All of the diffraction peaks on the curve of the pure $\mathrm{NaYF}_{4}: \mathrm{Yb}^{3+}, \mathrm{Tm}^{3+} \mathrm{NPs}$ are in agreement with the characteristic peaks of cubic $\mathrm{NaYF}_{4}$ crystals (JCPDS-77-2042), indicating the high crystallinity of the as-synthesized UCLNPs. As expected, two sets of diffraction peaks exist for the $\mathrm{NaYF}_{4}: \mathrm{Yb}^{3+}, \mathrm{Tm}^{3+} / \mathrm{PS}$ hybrid nanofibers, which correspondingly originated from the cubic $\mathrm{NaYF}_{4}$ crystals and the semicrystalline PS polymer. The as-fabricated hybrid nanofiber was further observed with TEM, and the images are shown in Figure 1d. TEM revealed that the $\mathrm{NaYF}_{4}: \mathrm{Yb}^{3+}, \mathrm{Tm}^{3+}$ NPs embedded into the PS electrospun nanofiber aggregated to form clusters with sizes between 100 and $300 \mathrm{~nm}$ due to the high viscosity of the electrospun precursor solution, which strongly limits the dispersion degree of the $\mathrm{NaYF}_{4}: \mathrm{Yb}^{3+}, \mathrm{Tm}^{3+} \mathrm{NPs}$ in the DMF solution. These aggregated UCLNPs may result in an enhanced luminescence intensity compared with the dispersed NPs. The high-magnification TEM image of the red circle shown in Figure 1d demonstrates that the $\mathrm{NaYF}_{4}: \mathrm{Yb}^{3+}, \mathrm{Tm}^{3+} \mathrm{NPs}$ on the hybrid nanofiber surface are also covered by the PS polymer with the thickness of $1 \sim 3 \mathrm{~nm}$ (Supplementary Fig. S1). The selected area electron diffraction (SAED) pattern of an individual $\mathrm{NaYF}_{4}: \mathrm{Yb}^{3+}, \mathrm{Tm}^{3+} / \mathrm{PS}$ hybrid nanofiber further confirms the crystallinity of the $\mathrm{NaYF}_{4}$-based NPs in the nanofibers. Therefore, we conclude that the $\mathrm{NaYF}_{4}: \mathrm{Yb}^{3+}, \mathrm{Tm}^{3+} \mathrm{NPs}$ assembled into the PS electrospun nanofibers, forming a novel HFM. To generalize the model of a flexible UCL membrane, we also embedded $\mathrm{NaYF}_{4}: \mathrm{Yb}^{3+}, \mathrm{Er}^{3+} \mathrm{NPs}$ into PS electrospun nanofibers using the same synthesis method (Supplementary Fig. S2).

The UCL behaviors of the as-fabricated HFMs were studied in comparison with the corresponding UCLNPs dispersed in DMF solution and the pure PS nanofibrous membrane. As shown in Figure $2 \mathrm{a}$, there is no observable UCL property on the pure PS nanofibrous membrane under the excitation of 980-nm illumination. Notably, the PS film shows a high transmittance from the visible to the near-infrared region (Supplementary Fig. S3). After assembly of the $\mathrm{NaYF}_{4}: \mathrm{Yb}^{3+}, \mathrm{Tm}^{3+}$ NPs into the PS electrospun nanofibers, the HFMs exhibited a strong blue UCL when excited by a $980-n m$ laser diode (LD). This blue UCL is attributed to the ${ }^{1} \mathrm{G}_{4}-{ }^{3} \mathrm{H}_{6}$ transition of $\mathrm{Tm}^{3+}$ (refs. 17,31). Compared to the pure $\mathrm{NaYF}_{4}: \mathrm{Yb}^{3+}, \mathrm{Tm}^{3+} \mathrm{NPs}$, the intensity ratios of the ${ }^{1} \mathrm{I}_{6}-{ }^{3} \mathrm{~F}_{4},{ }^{1} \mathrm{D}_{2}-{ }^{3} \mathrm{H}_{6},{ }^{1} \mathrm{D}_{2}-{ }^{3} \mathrm{~F}_{4},{ }^{1} \mathrm{G}_{4}-{ }^{3} \mathrm{H}_{6},{ }^{3} \mathrm{~F}_{2}-{ }^{3} \mathrm{H}_{6}$ and ${ }^{3} \mathrm{~F}_{3}-$ ${ }^{3} \mathrm{H}_{6}$ to ${ }^{1} \mathrm{G}_{4}-{ }^{3} \mathrm{~F}_{4}$ emissions decreased in the $\mathrm{NaYF}_{4}: \mathrm{Yb}^{3+}, \mathrm{Tm}^{3+} / \mathrm{PS}$ hybrid membrane. This phenomenon suggests that some vibrational transitions from the chemical bonds (or groups) of the PS polymer may interact with the excited levels of the surrounding $\mathrm{NaYF}_{4}: \mathrm{Yb}^{3+}$, $\mathrm{Tm}^{3+} \mathrm{NPs}$ via a nonradiative energy transfer process, leading to changes in the UCL spectra from the corresponding energy level transitions of $\mathrm{Tm}^{3+}$ (refs. 17,31). Based on this energy transfer process, the relative intensities of ${ }^{2} \mathrm{H}_{11 / 2}-{ }^{4} \mathrm{I}_{15 / 2}$ and ${ }^{4} \mathrm{~S}_{3 / 2}-{ }^{4} \mathrm{I}_{15 / 2}$ to ${ }^{4} \mathrm{~F}_{9 / 2}-{ }^{4} \mathrm{I}_{15 / 2}$ that were emitted from the $\mathrm{NaYF}_{4}: \mathrm{Yb}^{3+}, \mathrm{Er}^{3+} \mathrm{NPs}$ were significantly enhanced after coating the PS polymer (detailed analysis is provided in the supporting information, Supplementary Figs. S4 and S5). The $\mathrm{NaYF}_{4}: \mathrm{Yb}^{3+}, \mathrm{Er}^{3+} / \mathrm{PS}$ hybrid membrane displays a promoted green emission under 980-nm LD excitation (Figure $2 b)^{31,32}$. Embedding the UCLNPs into the polymer matrix effectively suppresses the local thermal effect driven by the LD excitation. This process also plays a role on promoting the UCL properties of the $\mathrm{NaYF}_{4} \mathrm{NPs}$, based on the cross relaxation ${ }^{31}$. When we excited the products with $980-\mathrm{nm} \mathrm{LD}$, the blue and green light spots of a diameter of $\sim 0.8 \mathrm{~cm}$ were clearly observed on the $\mathrm{NaYF}_{4}: \mathrm{Yb}^{3+}, \mathrm{Tm}^{3+} / \mathrm{PS}$ and $\mathrm{NaYF}_{4}: \mathrm{Yb}^{3+}, \mathrm{Er}^{3+} / \mathrm{PS}$ HFM surfaces, respectively (insets of Figure $2 \mathrm{a}$ and $2 \mathrm{~b}$ ). These observations further demonstrate the formation of UCNPs/PS HFMs, and this also provided an opportunity to implement UCL detection.

The surface wettability of the as-electrospun HFMs was investigated using water contact angle (WCA) measurements. The WCA results and selected water droplet images that were tested on different positions of the HFM are shown in Figure 2c. All of the water droplets erect on the membrane surfaces with an average CA of $\sim 153^{\circ}$, which implies that a superhydrophobic surface on the UCL membrane was constructed via the rational combination of the low surface energy of the polymer and the unique hierarchical micro-/ nanostructures of the electrospun fibrous membrane. The aselectrospun UCL membrane, which is interweaved by the randomlyoriented PS nanofibers, possesses a relatively rough surface compared with the flat PS film. This may result in a decreased contact area between the water droplet and the electrospun PS membrane by trapping the air bubbles in the spaces between the interweaved PS fibers. According to the Casssie-Baxter equation ${ }^{39-42}: \cos \theta^{\star}=f_{1} \cos \theta$ $f_{2}$, where $\theta^{*}$ and $\theta$ are the WCA on a flat and rough surface, respectively, and $f_{1}$ and $f_{2}$ are the fractions of liquid/solid and liquid/ gas contact areas, for which $f_{1}+f_{2}=1$. We conclude that an electrospun membrane with a rough surface could enhance the hydrophobic property of the PS polymer by either decreasing the liquid/solid 
a

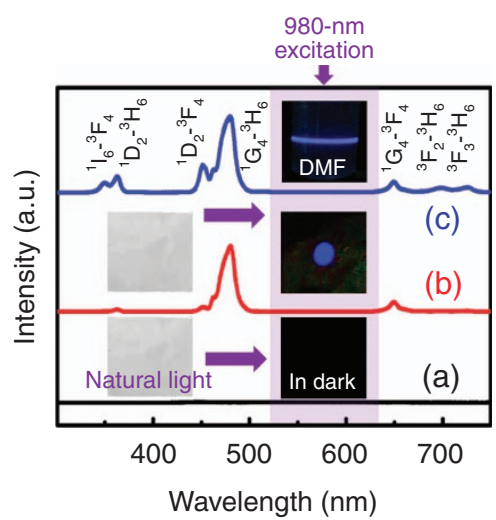

C

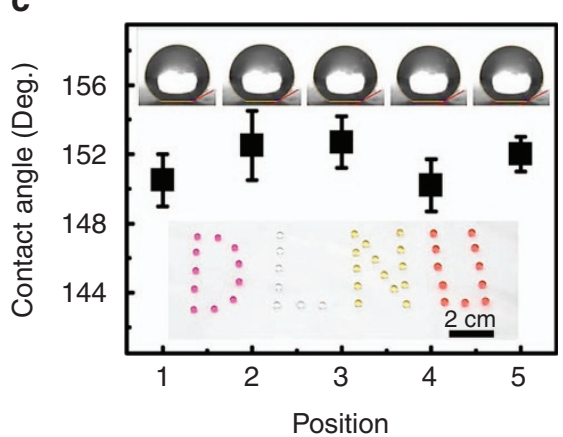

b

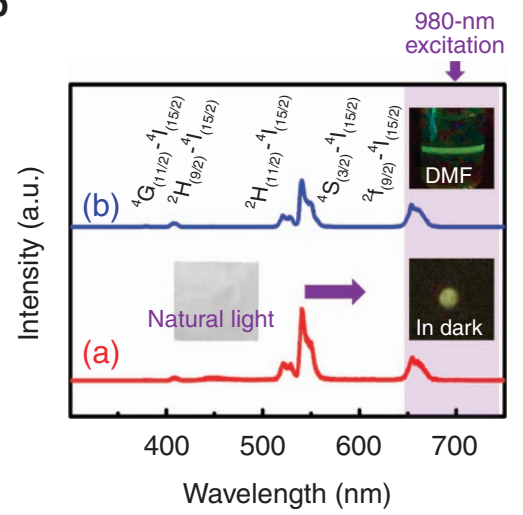

d

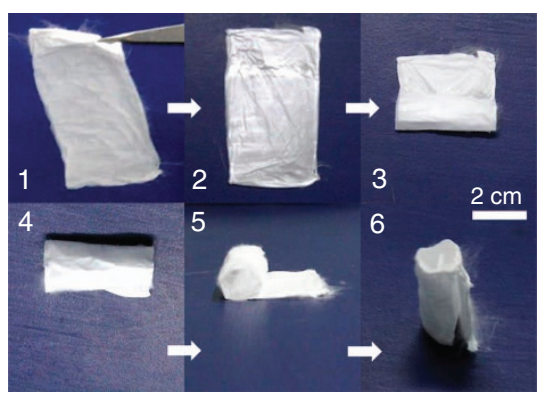

Figure 2 (a) Normalized UC emission spectra of (a) the PS nanofibrous membrane; (b) the $\mathrm{NaYF}_{4}: \mathrm{Yb}^{3+}, \mathrm{Tm}^{3+} / \mathrm{PS}_{\mathrm{HFM}}$ and (c) the $\mathrm{NaYF}_{4}: \mathrm{Yb}^{3+}$, $\mathrm{Tm}^{3+}$ NPs dispersed in DMF solution. The insets show the corresponding optical images obtained under natural-light or 980-nm LD irradiation. (b) Normalized UC emission spectra of (a) the $\mathrm{NaYF}_{4}: \mathrm{Yb}^{3+}, \mathrm{Er}^{3+} / \mathrm{PS}$ HFM and (b) the $\mathrm{NaYF}_{4}: \mathrm{Yb}^{3+}, \mathrm{Er}^{3+} \mathrm{NPs}$ dispersed in DMF solution. The insets show the corresponding optical images obtained under natural-light or 980-nm LD irradiation. (c) Contact angles and the corresponding optical profiles (and image) of water droplets on the different positions of the HFM surface; (d) Optical images of the tailored HFM with different morphologies.

contact areas or increasing the liquid/gas contact areas. Thus, water droplets with a quasi-spherical shape can be easily aligned on the HFM surfaces with designed patterns. For example, the four letters 'DLUN' were patterned, as shown in Figure 2c. Using the advantage of the superhydrophobic surface, the dye or biomolecules that were dissolved in the water droplets were carried away after detection, therefore produce a self-cleaning function for the UCL membrane. In addition, as a result of the free-standing and flexible properties for the electrospun polymer membrane, we could tailor or process these membranes into arbitrary structural shapes on the macroscopic scale, such as a rectangle, zigzag forms, a cylinder, etc (Figure 2d).

Engineering and integrating the well-designed functional properties in the as-fabricated solid membrane may produce new ideas for sensing fluorescence molecules from a single water droplet. Here, we used aqueous solutions of avidin and $\mathrm{RhB}$ as the target liquid to evaluate the sensitive performance of the as-fabricated UCL membrane. Avidin is a common fluorescence biomolecule with a wide light-absorption band that overlaps with the UC emission spectrum of the $\mathrm{NaYF}_{4}: \mathrm{Yb}^{3+}, \mathrm{Tm}^{3+} / \mathrm{PS}$ HFM in the blue light region. Meanwhile, the absorption peak of $\mathrm{RhB}$ has a certain degree of overlap with the $\mathrm{UC}$ emission spectrum of the $\mathrm{NaYF}_{4}: \mathrm{Yb}^{3+}, \mathrm{Er}^{3+} / \mathrm{PS} \mathrm{HFM}$ in the green light region (Figure 3a). The overlapped spectra of the UCL membrane (as the donor) and the fluorescence molecule (as the acceptor) may induce an energy transfer process via long-range dipole-dipole interactions, the so-called FRET, which will enhance the luminescence emission intensity from the fluorophore at a very low concentration ${ }^{24,27-29}$. To fulfill this energy transfer process, another essential condition is to maintain the distance between the donor and acceptor fluorophores to within a few nanometers ${ }^{43-46}$. As shown in the TEM images of the as-fabricated hybrid nanofibers (Supplementary Fig. S1), some of the UCLNPs are exposed on the nanofiber surfaces with a PS coating layer that is thinner than $3 \mathrm{~nm}$. Therefore, in our case, the FRET process occurs when loading the target droplet on the surface of the as-fabricated membrane to perform the UCL detection. Upon irradiation with visible light with photon energies that are equal to the main UC emission from the UCL membranes ( $480 \mathrm{~nm}$ for the $\mathrm{NaYF}_{4}: \mathrm{Yb}^{3+}, \mathrm{Tm}^{3+} / \mathrm{PS} \mathrm{HFM}$ and $540 \mathrm{~nm}$ for the $\mathrm{NaYF}_{4}: \mathrm{Yb}^{3+}, \mathrm{Er}^{3+} / \mathrm{PS} \mathrm{HFM}$ ), the photoluminescence (PL) bands for the aqueous solution of avidin and $\mathrm{RhB}$ should be $\sim 525$ and $610 \mathrm{~nm}$, respectively (Figure $3 \mathrm{~b}$ ).

Based on the above results and analyses, we conducted fluorescence sensing tests on a single water droplet containing trace amounts of fluorescence molecules by using the as-fabricated UCL membranes as the sensors. The schematic diagram of the fluorescence measurement is presented in Figure $3 \mathrm{c}$ in which the optical signals generated from both the UCL membrane and the detecting droplet are detected simultaneously. As observed in Figure 3d, upon excitation of the avidin droplet-loaded $\mathrm{NaYF}_{4}: \mathrm{Yb}^{3+}, \mathrm{Tm}^{3+} / \mathrm{PS}$ HFM with the $980-\mathrm{nm}$ $\mathrm{LD}$, a new PL emission band at $\sim 530 \mathrm{~nm}$ emerged in the emission spectrum in comparison with that of the pure $\mathrm{NaYF}_{4}: \mathrm{Yb}^{3+}, \mathrm{Tm}^{3+} / \mathrm{PS}$ HFM. Furthermore, by increasing the avidin concentration in the water droplet, the blue thulium emission centered at $480 \mathrm{~nm}$ decreased gradually, and the avidin emission peak at $\sim 530 \mathrm{~nm}$ increased accordingly. No emission from either avidin or RhB was observed under 980 -nm irradiation because there is almost no light absorption in this wavelength region for these fluorophores. Thus, the 
feature fluorescence group of the avidin molecule in the water droplet absorbed the photon energy in the blue region that was generated from the 980-nm-excited $\mathrm{NaYF}_{4}: \mathrm{Yb}^{3+}, \mathrm{Tm}^{3+} / \mathrm{PS}$ HFM that overlapped with its absorption spectrum. It then emitted lower-energy green-light photons via a down-conversion luminescence process. Thus, we easily sensed relevant bioluminescence information from a target droplet by detecting variations in the fluorescence intensities using the UCL
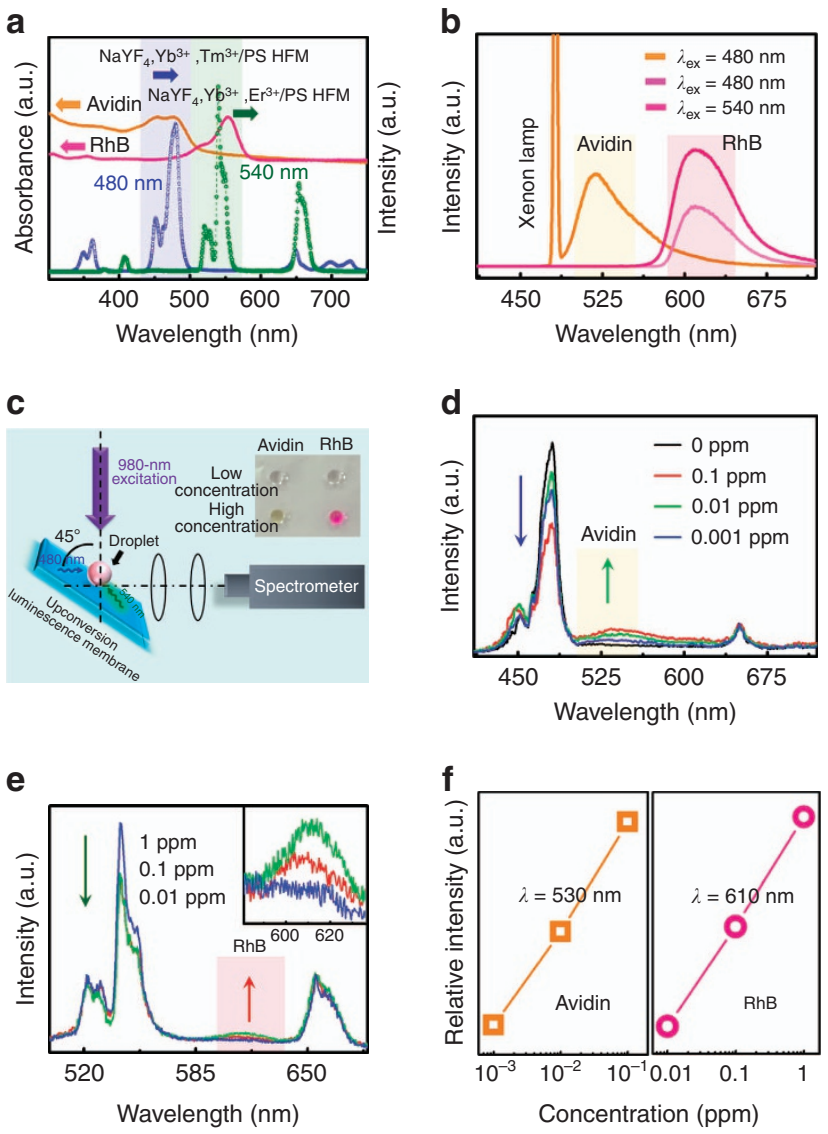

Figure 3 (a) Spectral overlap between the UC emission spectra of the aselectrospun HFMs $\left(\mathrm{NaYF}_{4}: \mathrm{Yb}^{3+}, \mathrm{Tm}^{3+} / \mathrm{PS}\right.$ (blue line), the $\mathrm{NaYF}_{4}: \mathrm{Yb}^{3+}$, $\mathrm{Er}^{3+} / \mathrm{PS} \mathrm{HFM}$ (green line)) and the UV-Vis absorption spectra of RhB and avidin aqueous solutions; (b) emission spectra of RhB and avidin aqueous solutions upon excitation at 480 and $540 \mathrm{~nm}$; (c) schematic diagram of the fluorescence measurement on the single water droplet; (d) normalized UC emission spectra of the $\mathrm{NaYF}_{4}: \mathrm{Yb}^{3+}, \mathrm{Tm}^{3+} / \mathrm{PS}$ HFM loaded with a single water droplet containing different concentrations of avidin; (e) normalized UC emission spectra of the $\mathrm{NaYF}_{4}: \mathrm{Yb}^{3+}, \mathrm{Er}^{3+} / \mathrm{PS}$ HFM loaded with a single water droplet containing different concentrations of $\mathrm{RhB}$; (f) the integrated luminescence intensities of avidin and RhB aqueous solution versus their corresponding concentration changes. membrane as a free-standing solid sensor. To further strengthen this conclusion, we detected a water droplet containing different concentrations of $\mathrm{RhB}$ by using the $\mathrm{NaYF}_{4}: \mathrm{Yb}^{3+}, \mathrm{Er}^{3+} / \mathrm{PS} \mathrm{HFM}$ under irradiation of $980 \mathrm{~nm}$. As expected, the characteristic fluorescence band of $\mathrm{RhB}$ that centered at $\sim 610 \mathrm{~nm}$ was observable in the emission spectrum of the UCL membrane. Meanwhile, this emission band increased gradually with the RhB concentration, which was accompanied by the decrease in the green erbium emission centered at $540 \mathrm{~nm}$ (Figure 3e). Thus, based on the FRET process between the UCL membrane donor and the fluorescence molecule acceptor, UCL detection on a single water droplet was successfully achieved using the as-fabricated HFM sensor. Notably, this new sensor exhibited not only an excellent linear relationship between the luminescence intensity (detecting the emission peak at 530 and $610 \mathrm{~nm}$ for avidin and RhB, respectively) and the concentration of the target fluorescence molecules (Figure 3f) but also at ultra-low detection limits (or ultra-high sensitivity), such as at $1 \mathrm{ppb}$ for avidin and $10 \mathrm{ppb}$ for RhB. However, it is difficult to detect the available information from the fluorescent molecule solution with a concentration that is equal to the above values by using pure UCLNPs as the sensors (Supplementary Fig. S6). Therefore, after strategic integration of the UCLNPs into the PS electrospun fibrous membrane that had unique hierarchical micro-/ nanostructures, the sensing performance on the fluorescence molecules was significantly improved. The detection limits are lower than most of the reported limit concentrations detected by other types of fluorescent sensors that are based on UCL materials (Table 1).

To determine the influence of the FRET process on the UCL detection more clearly, a control experiment was implemented in which the $\mathrm{NaYF}_{4}: \mathrm{Yb}^{3+}, \mathrm{Tm}^{3+} / \mathrm{PS}$ HFM was used as the sensor to detect the $\mathrm{RhB}$ droplet. The results show that a characteristic fluorescence band that belongs to the $\mathrm{RhB}$ molecule appears on the emission spectrum of the $\mathrm{NaYF}_{4}: \mathrm{Yb}^{3+}, \mathrm{Tm}^{3+} / \mathrm{PS}$ HFM under 980-nm irradiation. Meanwhile, the luminescence intensity is still dependent on the concentration changes of the $\mathrm{RhB}$ droplet and inversely proportional to the intensity of the ${ }^{1} \mathrm{G}_{4}-{ }^{3} \mathrm{H}_{6}$ emission band of the $\mathrm{Tm}^{3+}$ ion, which peaked at $480 \mathrm{~nm}$ (Supplementary Fig. S7). There is no FRET process between the $\mathrm{NaYF}_{4}: \mathrm{Yb}^{3+}, \mathrm{Tm}^{3+} / \mathrm{PS}$ HFM and the RhB molecules due to their mismatched spectral characteristics, as shown in Figure $3 \mathrm{a}$. Therefore, the higher-energy blue photons emitted from the $\mathrm{NaYF}_{4}$ : $\mathrm{Yb}^{3+}, \mathrm{Tm}^{3+} / \mathrm{PS}$ HFM under excitation of $980 \mathrm{~nm}$ can induce interband transitions of the RhB molecules, resulting in the emission of lowerenergy photons at $\sim 610 \mathrm{~nm}$, according to the stokes shift rule. Further investigation found that the $\mathrm{RhB}$ emission peak shifted gradually towards the longer wavelength side with increasing concentration (Supplementary Fig. S7). This can be attributed to the reabsorption effect of the dye ${ }^{47}$. However, when the concentration of $\mathrm{RhB}$ was lower than $10 \mathrm{ppm}$ in the water droplet, no trace of fluorescence emission related to the RhB was detected in the spectrum. The above observation demonstrates that the detection limit (or the sensitivity) of

Table 1 Structure and detection parameters of the UC fluorescent sensors

\begin{tabular}{|c|c|c|c|c|}
\hline Material & Sensor type & Fluorescent molecule & Detection limit & Ref. \\
\hline $\mathrm{NaYF}_{4}: \mathrm{Yb}, \mathrm{Er}$ & Particle & R6G & $\sim 110 \mathrm{ppm}$ & 28 \\
\hline NaYF4:Ce/Tb & Nanoparticle & Avidin & 0.34 ppm & 25 \\
\hline $\mathrm{Y}_{2} \mathrm{O}_{2} \mathrm{~S}: \mathrm{Yb}, \mathrm{Er}$ & Particle & Phycobiliprotein & $\sim 0.07 \mathrm{ppm}$ & 26 \\
\hline $\mathrm{NaYF}_{4}: \mathrm{Yb}, \mathrm{Tm} / \mathrm{TiO}_{2}$ & Solid film & Avidin & $\sim 3.3 \mathrm{ppb}$ & 29 \\
\hline $\mathrm{NaYF}_{4}: \mathrm{Yb}, \mathrm{Tm} / \mathrm{PS}$ & Fibrous membrane & Avidin & $\sim 1 \mathrm{ppb}$ & Our work \\
\hline $\mathrm{NaYF}_{4}: \mathrm{Yb}, \mathrm{Er} / \mathrm{PS}$ & Fibrous membrane & RhB & $\sim 10 \mathrm{ppb}$ & Our work \\
\hline
\end{tabular}


a

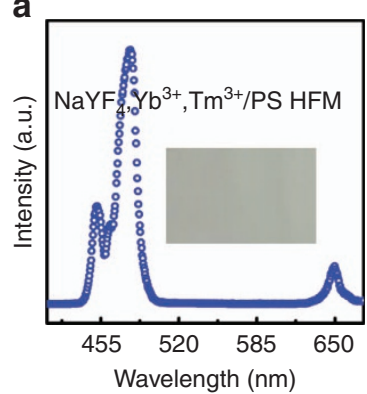

C
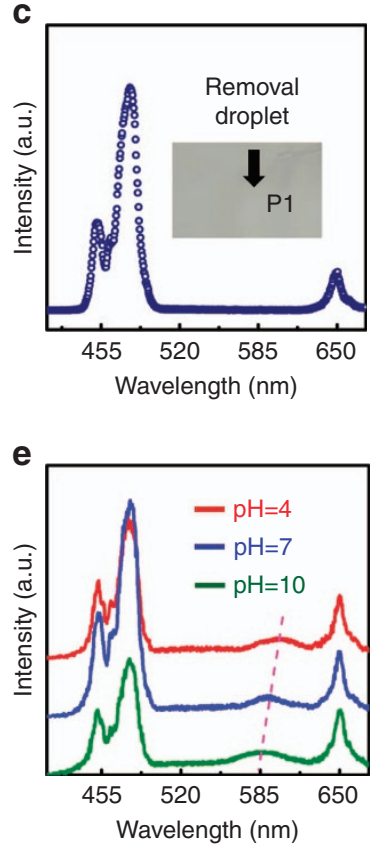

b

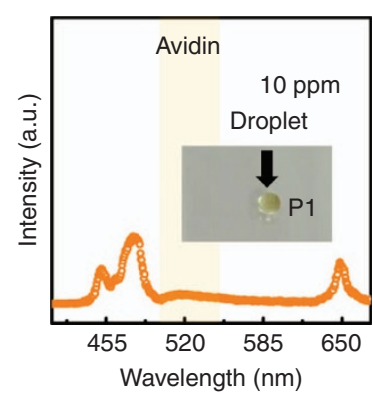

d

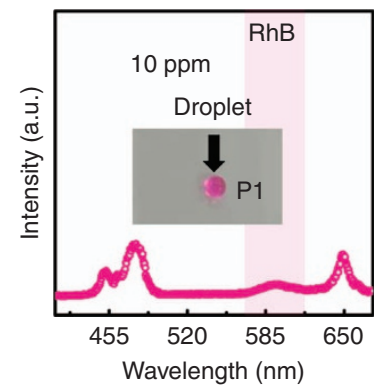

f

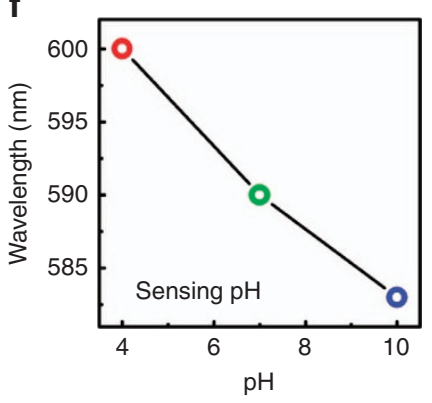

Figure 4 In situ UC emission spectra and the corresponding optical image of (a) the $\mathrm{NaYF}_{4}: \mathrm{Yb}^{3+}, \mathrm{Tm}^{3+} / \mathrm{PS} \mathrm{HFM}$; (b) the $\mathrm{NaYF}_{4}: \mathrm{Yb}^{3+}, \mathrm{Tm}^{3+} / \mathrm{PS} \mathrm{HFM}$ loaded with a single avidin droplet; (c) the $\mathrm{NaYF}_{4}: \mathrm{Yb}^{3+}, \mathrm{Tm}^{3+} / \mathrm{PS}$ HFM after removal of the above avidin droplet via pipette and (d) the $\mathrm{NaYF}_{4}: \mathrm{Yb}^{3+}, \mathrm{Tm}^{3}$ +/PS HFM loaded with a single RhB droplet; (e) spectral evolution on the normalized UC emission of the $\mathrm{NaYF}_{4}: \mathrm{Yb}^{3+}, \mathrm{Tm}^{3+}$ PS HFM loaded with $\mathrm{RhB}$ droplets at different $\mathrm{pHs}$; (f) the emission peak positions of RhB versus the corresponding $\mathrm{pHs}$ changes in the $\mathrm{RhB}$ droplet.

the UCL membrane on the water droplet increased (or decreased) in the absence of a FRET process between the UCL membrane and the fluorescence molecules.

For a traditional liquid-based detection system, a UCL nanocrystal sensor suspended in the target solution is easily contaminated or lost during the detecting process, which is the main drawback that limits its recyclability ${ }^{28,29}$. Thus, the development of a novel solid-based detection system with excellent recyclability is desirable. This may lead to new applications for UCL sensors in the fields of biological or medical detection. To evaluate the recyclability of the as-fabricated UCL membrane, we conducted an in situ spectral measurement on the $\mathrm{NaYF}_{4}: \mathrm{Yb}^{3+}, \mathrm{Tm}^{3+} / \mathrm{PS}$ HFM loaded with the avidin and $\mathrm{RhB}$ droplet alternately. As mentioned, the photon energy, which is emitted from the $\mathrm{NaYF}_{4}: \mathrm{Yb}^{3+}, \mathrm{Tm}^{3+} / \mathrm{PS} \mathrm{HFM}$ by up-converting the nearinfrared photon at $980 \mathrm{~nm}$, is higher than the energy required to excite the interband transitions of both avidin and $\mathrm{RhB}$. Thus, the characteristic fluorescence band of either the avidin or RhB droplet should be detected by using the $\mathrm{NaYF}_{4}: \mathrm{Yb}^{3+}, \mathrm{Tm}^{3+} / \mathrm{PS}$ HFM.

As shown in Figure $4 \mathrm{a}$, the clean $\mathrm{NaYF}_{4}: \mathrm{Yb}^{3+}, \mathrm{Tm}^{3+}$ /PS HFM exhibits a classic UC emission spectrum of $\mathrm{Tm}^{3+}$ ions upon irradiation at $980 \mathrm{~nm}$. When an avidin droplet (10 ppm) was loaded onto the HFM surface with the position at P1, the avidin emission peak at $\sim 525 \mathrm{~nm}$ appeared, and the blue thulium emission centered at $480 \mathrm{~nm}$ decreased accordingly (Figure 4b). After removal of this avidin droplet via pipette, the emission spectrum of the $\mathrm{NaYF}_{4}: \mathrm{Yb}^{3+}, \mathrm{Tm}^{3+} / \mathrm{PS}$ HFM was restored to the characteristic emission profile of the $980-\mathrm{nm}$ excited $\mathrm{Tm}^{3+}$ (Figure 3c). Meanwhile, the corresponding optical image indicates the self-cleaning property of the superhydrophobic membrane sensor (inset in Figure 3c). Interestingly, upon injecting another droplet containing $\mathrm{RhB}(10 \mathrm{ppm})$ on the $\mathrm{P} 1$ position of the $\mathrm{NaYF}_{4}: \mathrm{Yb}^{3+}, \mathrm{Tm}^{3+} / \mathrm{PS} \mathrm{HFM}$, the characteristic fluorescence band of $\mathrm{RhB}$ was observed without any noise. Correspondingly, the luminescence intensity of the ${ }^{1} \mathrm{G}_{4}-{ }^{3} \mathrm{H}_{6}$ transition of $\mathrm{Tm}^{3+}$ significantly decreased (Figure 4d). Thus, we conclude that this high-sensitive UCL membrane sensor exhibits excellent recyclability, which has not been achieved using traditional liquid-based detection systems. Moreover, by using this type of flexible and free-standing UCL membrane (for example, $\mathrm{NaYF}_{4}: \mathrm{Yb}^{3+}, \mathrm{Tm}^{3+} / \mathrm{PS} \mathrm{HFM}$ ) as the sensor, the $\mathrm{pH}$ of the single droplet can be extracted by detecting the spectral evolution on the characteristic fluorescent peak of $\mathrm{RhB}$. Generally, some functional groups in dye molecules, such as the carboxylic group in $\mathrm{RhB}$, can be protonated in solution. We can therefore change the fluorescence characteristics of dye molecules according to the concentration of dissociative $\mathrm{H}^{+}$(refs. 48,49). As shown in Figure 4e, upon increasing the $\mathrm{pH}$ in the target droplet, the fluorescence peak position of the RhB molecule gradually blue shifts. Further investigation indicates a good linear relation between the fluorescence peak position of the $\mathrm{RhB}$ molecule and the $\mathrm{pH}$ of the water droplet (Figure $4 \mathrm{f}$ ), suggesting reliable performance for the UCL membrane sensor. Overall, this type of flexible, free-standing and superhydrophobic UCL membrane possesses ultra-high sensitivity, good linearity and excellent recyclability for biological or medical detection on a single droplet. In addition, single droplet detection can significantly save the consumption of a target solution during UCL biodetection, which is far more advanced than traditional liquid-based detection systems that require a large amount of target solution.

\section{CONCLUSIONS}

We developed a novel solid state UCL biosensor that was fabricated by embedding UCLNP clusters into a transparent PS nanofibrous-matrix to form a flexible, free-standing and tailorable HFM. The PS-covered clusters consisted of $\mathrm{NaYF}_{4}: \mathrm{Yb}^{3+}, \mathrm{Tm}^{3+}$ (or $\mathrm{Er}^{3+}$ ) NPs that contributed to the UCL property of the as-electrospun HFM. Moreover, the rational combination of the low surface energy of the polymer PS and the unique hierarchical micro-/nanostructures of the electrospun fibrous membrane results in superhydrophobicity for this UCL membrane. These advantages make this hybrid nanomaterial a highperformance UCL biosensor for single droplet detection. Meanwhile, this high-performance UCL sensor also exhibits excellent recyclability due to its superhydrophobic self-cleaning surface.

\section{CONFLICT OF INTEREST}

The authors declare no conflict of interest.

\section{ACKNOWLEDGEMENTS}

This work is supported by the National Natural Science Foundation of China (Grant Nos. 51402038, 11474046 and 11274057), the Program for New Century Excellent Talents in University (NCET-13-0702), the Technology Foundation for Selected Overseas Chinese Scholars from the Ministry of Personnel of 
China, the Scientific Research Foundation for Doctors of Liaoning Province (Grant No. 20141118), the Educational Committee Foundation of Liaoning Province (Grant No. L2014547), the Science and Technology Project of Liaoning Province (Grant No. 2012222009), the Program for Liaoning Excellent Talents in University (LNET) (Grant No. LR2015016), the Science and Technique Foundation of Dalian (Grant Nos. 2014J11JH134 and 2015J12JH201) and the Fundamental Research Funds for Central Universities (Grant Nos. DC201502080203 and DC201502080304).

1 Avouris P, Freitag M, Perebeinos V. Carbon-nanotube photonics and optoelectronics. Nat Photonics 2008; 2: 341-350.

2 Zhou PW, Zhou DL, Tao L, Zhu YS, Xu W et al. 320-fold luminescence enhancement of $\left[\mathrm{Ru}(\mathrm{dpp})_{3}\right] \mathrm{Cl}_{2}$ dispersed on PMMA opal photonic crystals and highly improved oxygen sensing performance. Light Sci App/ 2014; 3: e209, doi:10.1038/Isa.2014.90.

3 Huang XY, Han SY, Huang W, Liu XG. Enhancing solar cell efficiency: the search for luminescent materials as spectral converters. Chem Soc Rev 2013; 42: 173-201.

4 Gai SL, Li CX, Yang PP, Lin J. Recent progress in rare earth micro/nanocrystals: soft chemical synthesis, luminescent properties, and biomedical applications. Chem Rev 2014; 114: 2343-2389.

5 Huang P, Zheng W, Zhou SY, Tu DT, Chen Z et al. Lanthanide-doped LiLuF 4 upconversion nanoprobes for the detection of disease biomarkers. Angew Chem Int Ed Engl 2014; 53: 1252-1257.

6 Hou ZY, Li CX, Ma PA, Li GG, Cheng ZY et al. Electrospinning preparation and drugdelivery properties of an up-conversion luminescent porous $\mathrm{NaYF}_{4}: \mathrm{Yb}^{3+}, \mathrm{Er}^{3+} @$ silica fiber nanocomposite. Adv Funct Mater 2011; 21: 2356-2365.

7 Liu T, Bai X, Miao C, Dai QL, Xu W et al. $\mathrm{Yb}_{2} \mathrm{O}_{3} / \mathrm{Au}$ upconversion nanocomposites with broad-band excitation for solar cells. J Phys Chem C 2014; 118: 3258-3265.

8 Zhang X, Yang PP, Dai YL, Ma PA, Li XJ et al. Multifunctional up-converting nanocomposites with smart polymer brushes gated mesopores for cell imaging and thermo/ pH dual-responsive drug controlled release. Adv Funct Mater 2013; 23: 4067-4078.

9 Ma PA, Xiao HH, Li XX, Li CX, Dai YL et al. Rational design of multifunctional upconversion nanocrystals/polymer nanocomposites for cisplatin (IV) delivery and biomedical imaging. Adv Mater 2013; 25: 4898-4905.

10 Tang YN, Di WH, Zhai XS, Yang RY, Qin WP. NIR-responsive photocatalytic activity and mechanism of $\mathrm{NaYF}_{4}$ : Yb, Tm@TiO 2 core-shell nanoparticles. ACS Catal 2013; 3: 405-412.

11 Xu S, Xu SH, Zhu YS, Xu W, Zhou PW et al. A novel upconversion, fluorescence resonance energy transfer biosensor (FRET) for sensitive detection of lead ions in human serum. Nanoscale 2014; 6: 12573-12579.

12 Chen BT, Dong B, Wang J, Zhang S, Xu L et al. Amphiphilic silane modified NaYF 4 : Yb, Er loaded with $\mathrm{Eu}(\mathrm{TTA})_{3}(\mathrm{TPPO})_{2}$ nanoparticles and their multi-functions: dual mode temperature sensing and cell imaging. Nanoscale 2013; 5: 8541-8549.

$13 \mathrm{Li}$ ZQ, Zhang Y, Jiang S. Multicolor core/shell-structured upconversion fluorescent nanoparticles. Adv Mater 2008; 20: 4765-4769.

14 Vetrone F, Naccache R, de la Fuente AJ, Sanz-Rodríguez F, Blazquez-Castro A et al. Intracellular imaging of $\mathrm{HeLa}$ cells by non-functionalized $\mathrm{NaYF}_{4}$ : $\mathrm{Er}^{3+}, \mathrm{Yb}^{3+}$ upconverting nanoparticles. Nanoscale 2010; 2: 495-498.

15 Liu Q, Sun Y, Yang TS, Feng W, Li CG et al. Sub-10 nm hexagonal lanthanide-doped $\mathrm{NaLuF}_{4}$ upconversion nanocrystals for sensitive bioimaging in vivo. J Am Chem Soc 2011; 133: 17122-17125.

16 Feng W, Sun LD, Yan $\mathrm{CH}$. Ag nanowires enhanced upconversion emission of $\mathrm{NaYF}_{4}$ : Yb, Er nanocrystals via a direct assembly method. Chem Commun 2009; 29: 4393-4395.

17 Wang F, Liu XG. Upconversion multicolor fine-tuning: visible to near-infrared emission from lanthanide-doped $\mathrm{NaYF}_{4}$ nanoparticles. J Am Chem Soc 2008; 130: 5642-5643.

18 Liu XM, Zhao JW, Sun YJ, Song K, Yu Y et al. Ionothermal synthesis of hexagonal-phase $\mathrm{NaYF}_{4}: \mathrm{Yb}^{3+}, \mathrm{Er}^{3+} / \mathrm{Tm}^{3+}$ upconversion nanophosphors. Chem Commun 2009; 43: 6628-6630

19 Burns JH. Crystal structure of hexagonal sodium neodymium fluoride and related compounds. Inorg Chem 1965; 4: 881-886.

20 Zhang JH, Hao ZD, Li J, Zhang X, Luo YS et al. Observation of efficient population of the red-emitting state from the green state by non-multiphonon relaxation in the $\mathrm{Er}^{3+-} \mathrm{Yb}^{3+}$ system. Light Sci App/ 2015; 4: e239, doi:10.1038/lsa.2015.12.

21 Qin WP, Liu ZY, Sin CN, Wu CF, Qin GS et al. Multi-ion cooperative processes in $\mathrm{Yb}^{3+}$ clusters. Light Sci App/ 2014; 3: e193, doi:10.1038/lsa.2014.74.

22 Bakalova R, Ohba H, Zhelev Z, Ishikawa M, Baba Y. Quantum dots as photosensitizers? Nat Biotechnol 2004; 22: 1360-1361.

23 Liu JL, Liu Y, Liu Q, Li CY, Sun LN et al. Iridium(III) complex-coated nanosystem for ratiometric upconversion luminescence bioimaging of cyanide anions. J Am Chem Soc 2011; 133: 15276-15279.

24 Chen R, Shen YQ, Xiao F, Liu B, Gurzadyan GG et al. Surface Eu-treated ZnO nanowires with efficient red emission. J Phys Chem C 2010; 114: 18081-18084.
25 Tu DT, Liu LQ, Ju Q, Liu YS, Zhu HM et al. Time-resolved FRET biosensor based on amine-functionalized lanthanide-doped $\mathrm{NaYF}_{4}$ nanocrystals. Angew Chem Int Ed Eng 2011; 50: 6306-6310.

26 Kuningas K, Rantanen T, Ukonaho T, Lövgren T, Soukka T. Homogeneous assay technology based on upconverting phosphors. Anal Chem 2005; 77: 7348-7355.

27 Xiao F, Chen R, Shen YQ, Dong ZL, Wang HH et al. Efficient energy transfer and

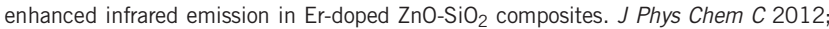
116: 13458-13462.

28 Chen R, Ta VD, Xiao F, Zhang QY, Sun HD. Multicolor hybrid upconversion nanoparticles and their improved performance as luminescence temperature sensors due to energy transfer. Small 2013; 9: 1052-1057.

$29 \mathrm{Xu} \mathrm{S}$, Xu W, Wang YF, Zhang S, Zhu YS et al. NaYF 4 : Yb, Tm nanocrystals and $\mathrm{TiO}_{2}$ inverse opal composite films: a novel device for upconversion enhancement and solid-based sensing of avidin. Nanoscale 2014; 6: 5859-5870.

30 Zhang ZY, Shao CL, Gao F, Li XH, Liu YC. Enhanced ultraviolet emission from highly dispersed $\mathrm{ZnO}$ quantum dots embedded in poly(vinyl pyrrolidone) electrospun nanofibers. J Colloid Interface Sci 2010; 347: 215-220.

31 Dong B, Song HW, Yu HQ, Zhang H, Qin RF et al. Upconversion properties of $\mathrm{Ln}^{3+}$ doped $\mathrm{NaYF}_{4} /$ polymer composite fibers prepared by electrospinning. J Phys Chem C 2008; 112: 1435-1440.

32 Zou $\mathrm{P}$, Hong X, Ding YD, Zhang ZY, Chu XY et al. Up-conversion luminescence of NaYF4: $\mathrm{Yb}^{3+} / \mathrm{Er}^{3+}$ nanoparticles embedded into PVP nanotubes with controllable diameters. J Phys Chem C 2012; 116: 5787-5791.

33 Sui XM, Shao CL, Liu YC. White-light emission of polyvinyl alcohol/ZnO hybrid nanofibers prepared by electrospinning. Appl Phys Lett 2005; 87: 113115.

34 Fridrikh SV, Yu JH, Brenner MP, Rutledge GC. Controlling the fiber diameter during electrospinning. Phys Rev Lett 2003; 90: 144502.

$35 \mathrm{He} \mathrm{D}, \mathrm{Hu}$ B, Yao QF, Wang K, Yu SH. Large-scale synthesis of flexible freestanding SERS substrates with high sensitivity: electrospun PVA nanofibers embedded with controlled alignment of silver nanoparticles. ACS Nano 2009; 3: 3993-4002.

36 Zhang CL, Lv KP, Cong HP, Yu SH. Controlled assemblies of gold nanorods in PVA nanofiber matrix as flexible free-standing SERS substrates by electrospinning. Small 2012; 8: 648-653.

37 Zhang CL, Lv KP, Hu NY, Yu L, Ren XF et al. Macroscopic-scale alignment of ultralong $\mathrm{Ag}$ nanowires in polymer nanofiber mat and their hierarchical structures by magneticfield-assisted electrospinning. Small 2012; 8: 2936-2940.

38 Zhang CL, Lv KP, Huang HT, Cong HP, Yu SH. Co-assembly of Au nanorods with Ag nanowires within polymer nanofiber matrix for enhanced SERS property by electrospinning. Nanoscale 2012; 4: 5348-5355.

39 Jiang L, Zhao Y, Zhai J. A lotus-leaf-like superhydrophobic surface: a porous microsphere/nanofiber composite film prepared by electrohydrodynamics. Angew Chem Int Ed Engl 2004; 43: 4338-4341.

40 Patankar NA. On the modeling of hydrophobic contact angles on rough surfaces. Langmuir 2003; 19: 1249-1253.

41 Wang LL, Zhang XT, Fu Y, Li B, Liu YC. Bioinspired preparation of ultrathin $\mathrm{SiO}_{2}$ shell on $\mathrm{ZnO}$ nanowire array for ultraviolet-durable superhydrophobicity. Langmuir 2009; 25: 13619-13624.

42 Muthiah P, Hsu SH, Sigmund W. Coaxially electrospun PVDF-teflon AF and teflon AF-PVDF core-sheath nanofiber mats with superhydrophobic properties. Langmuir 2010; 26: 12483-12487.

43 ThomasIII SW, Joly GD, Swager TM. Chemical sensors based on amplifying fluorescent conjugated polymers. Chem Rev 2007; 107: 1339-1386.

44 Feng FD, He F, An LL, Wang S, Li YL et al. Fluorescent conjugated polyelectrolytes for biomacromolecule detection. Adv Mater 2008; 20: 2959-2964.

45 Wang S, Bazan GC. Optically amplified RNA-protein detection methods using lightharvesting conjugated polymers. Adv Mater 2003; 15: 1425-1428.

46 Tang F, He F, Cheng HC, Li LD. Self-assembly of conjugated polymer-Ag@SiO 2 hybrid fluorescent nanoparticles for application to cellular imaging. Langmuir 2010; 26: 11774-11778.

47 He TC, Chen R, Lin WW, Huang F, Sun HD. Two-photon-pumped stimulated emission from ZnO single crystal. Appl Phys Lett 2011; 99: 081902.

48 Adachi K, Watanabe K, Yamazaki S. pH-responsive switchable aggregation phenomena of xanthene dyes adsorbed on tungsten(VI) oxide colloid surface. Ind Eng Chem Res 2014; 53: 13046-13057.

49 Dey D, Bhattacharjee D, Chakraborty S, Hussain SA. Effect of nanoclay laponite and $\mathrm{pH}$ on the energy transfer between fluorescent dyes. J Photoch Photobio A 2013; 252 $174-182$.

c) (i) $\Theta$ This work is licensed under a Creative Commons Attribution BY NC ND NonCommercial-NoDerivs 4.0 International License. The images or other third party material in this article are included in the article's Creative Commons license, unless indicated otherwise in the credit line; if the material is not included under the Creative Commons license, users will need to obtain permission from the license holder to reproduce the material. To view a copy of this license, visit http:// creativecommons.org/licenses/by-nc-nd/4.0/

Supplementary Information for this article can be found on the Light: Science \& Applications' website (http://www.nature.com/lsa). 